\title{
Acetylcholine iontophoresis in diabetic patients with and without peripheral neuropathy: a potential therapeutic tool Ibrahim Ismail Abu Zaid ${ }^{a}$, Mohamed Ahmed Hussein ${ }^{b}$, Gihan Samir Mousa ${ }^{c}$, Amany Raafat Mohamed ${ }^{d}$, Nagwa Mohamed Badrc, Alaa A. Hamid ${ }^{b}$
}

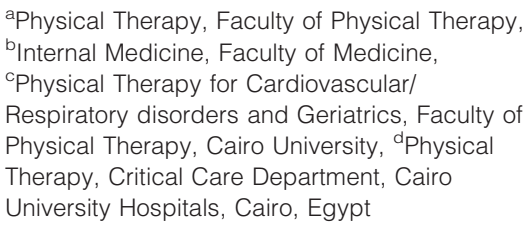

aphysical Therapy, Faculty of Physical Therapy, ${ }^{b}$ Internal Medicine, Faculty of Medicine, 'Physical Therapy for Cardiovascular/ Respiratory disorders and Geriatrics, Faculty of Physical Therapy, Cairo University, ${ }^{\mathrm{D}}$ Physical Therapy, Critical Care Department, Cairo University Hospitals, Cairo, Egypt

Correspondence to Mohamed A. Hussein, MD, MSc, Department of Internal Medicine, Cairo University, Cairo, Egypt. Tel: 01119110567 e-mail: m-ahmed79@cu.edu.eg

Received 28 July 2017

Accepted 14 August 2017

The Egyptian Journal of Internal Medicine 2018, 30:140-144

\begin{abstract}
Background
Iontophoresis had been widely used as a therapeutic option in the field of dermatology and physiotherapy. In vascular medicine, vasodilating response to acetylcholine $(\mathrm{ACh})$ iontophoresis had been also previously studied in the evaluation of endothelial dysfunction in diabetes mellitus and its microvascular complications but less was published about its therapeutic implementations. The current study aimed at investigating the therapeutic role of ACh iontophoresis in the improvement of endothelial dysfunction seen in diabetic patients with and without peripheral neuropathy (PN).

Patients and methods

Forty patients with type 2 diabetes mellitus, 20 with and 20 without $P N$, were subjected to a therapeutic program of $\mathrm{ACh}$ iontophoresis three times a week for 2 successive weeks 'long-term iontophoresis'. Percentage change in perfusion was measured in the two groups using laser Doppler flowmetry. Readings were taken pretreatment and posttreatment on three occasions: at baseline temperature, after local warming to $35^{\circ} \mathrm{C}$, and at maximal flow after exposure to ACh iontophoresis 'short-term iontophoresis'.

Results

Perfusion significantly improved after 2 weeks of therapy in the two groups with percentage change improvement of 180.65 vs. $131.50 \%$ in the baseline, 219.45 vs. $149.40 \%$ after local warming to $35^{\circ} \mathrm{C}$ and 269.60 vs. $236.95 \%$ after short-term $\mathrm{ACh}$ iontophoresis in patients without and those with $\mathrm{PN}$, respectively, with $P$ values of $0.0004,0.0005$, and 0.049 , respectively.

Conclusion

ACh iontophoresis may be an optional treatment procedure for improving cutaneous perfusion in diabetics for further randomized control studies.
\end{abstract}

\footnotetext{
Keywords: flowmetry, type 2 diabetes mellitus

Egypt J Intern Med 30:140-144

(c) 2018 The Egyptian Journal of Internal Medicine

$1110-7782$
}

acetylcholine iontophoresis, diabetic neuropathy, endothelial dysfunction, laser Doppler

\section{Introduction}

Iontophoresis is the process of delivery of a chemical substance to the skin through an electrical current applied through two adhesive electrodes depending on repulsive electromotive forces [1]. As a therapy, it was studied in the treatment of palmoplantar and axillary hyperhydrosis [2] plantar fasciitis [3], migraine [4], to enhance wound healing [5] and digital ischemia in systemic sclerosis [6].

In diabetes mellitus, acetylcholine ( $\mathrm{ACh}$ ) iontophoresis had been used in the assessment of cutaneous microcirculation and endothelial dysfunction [7-10] and its complications such as peripheral neuropathy (PN) $[11,12]$ but less was published regarding its therapeutic implementations.

\section{Patients and methods}

This observational case-control study was approved by the Research Ethics Committee for experimental and clinical studies at the Faculty of Medicine, Cairo University, Egypt. Patients were asked to give a written informed voluntary consent to participate in the study after full description of all procedures including possible risk of skin irritation during treatment time.

The study included 40 patients with type 2 diabetes mellitus enrolled from Kasr Al-Ainy diabetes outpatient clinics and inpatient wards of the Internal Medicine Department, Cairo University. They were divided into two groups: group I included 20 patients without PN and group II included 20 patients with PN diagnosed according to neuropathy symptom score, neuropathy disability

This is an open access journal, and articles are distributed under the terms of the Creative Commons Attribution-NonCommercial-ShareAlike 4.0 License, which allows others to remix, tweak, and build upon the work non-commercially, as long as appropriate credit is given and the new creations are licensed under the identical terms. 
score [13], and the 'yes or no' the Semmes-Weinstein monofilament test [14]. We excluded patients with diabetic autonomic neuropathy, skin allergy or inflammation, implanted cardiac pacemakers, peripheral vascular disease (PVD), unstable angina, and those with chronic renal impairment.

At the beginning, standard pulsed wave Doppler velocimetry was done for all patients using HDI 5000 echograph (ALT USA) color-coded duplex ultrasound to exclude PVD.

All patients were subjected to a three-step procedure:

\section{First evaluation procedure (pretreatment)}

Microcirculation blood flow was assessed using a single-point laser probe placed on the dorsum of the foot and a laser Doppler blood flow monitor (Periflux PF5000; Perimed, Sweden). Blood flow was measured in three situations: at room temperature ' $30^{\circ} \mathrm{C}$ ' (A) as a baseline measurement, after local warming to $35^{\circ} \mathrm{C}$ (B) for $3 \mathrm{~min}$, and lastly maximum flow was assessed using short-term $\mathrm{ACh}$ iontophoresis (C) delivered through a 'Perilont device' (Perimed, Sweden) apparatus applied at a current intensity of $0.4 \mathrm{~mA}$ for $3 \mathrm{~min}$ (Figure 1) [15].

\section{Treatment procedure}

Iontophoresis apparatus (Phyaction 787; Uniphy, Holland) was used to deliver ACh to the skin through an electrode placed on the medial side of the quadriceps muscle $(5 \mathrm{~cm}$ above the knee) in addition to another indifferent electrode attached to the medial side of the calf ( $5 \mathrm{~cm}$ below the knee) (Figure 2). A total of three sessions/week for 2 weeks were applied using a current intensity that ranged from 3 to $5 \mathrm{~mA}$ for $15 \mathrm{~min}$ per session (therapeutic long-term $\mathrm{ACh}$ iontophoresis).

To ensure sufficient safety of this treatment protocol (to avoid pain and burn), the following was considered $[16,17]:$

(1) A current intensity below the pain threshold that was comfortably tolerated by patients was applied (usually below $5 \mathrm{~mA}$ ).
(2) Low-voltage galvanic current stimulation was used.

(3) Decreased current intensity during treatment to accommodate for decrease in skin impedance.

(4) The current intensity should be gradually increased.

(5) Skin was checked every 3-5 min for any sign of irritation.

\section{Second evaluation procedure (post-treatment)}

Cutaneous blood flow was reassessed after the treatment protocol using the same laser probe at the same three occasions 'A, B, and C'.

\section{Results}

Group I included 12 (60\%) women and eight (40\%) men versus $13(65 \%)$ and seven (35\%) in group II; further demographic data are summarized in Table 1.

Figure 1

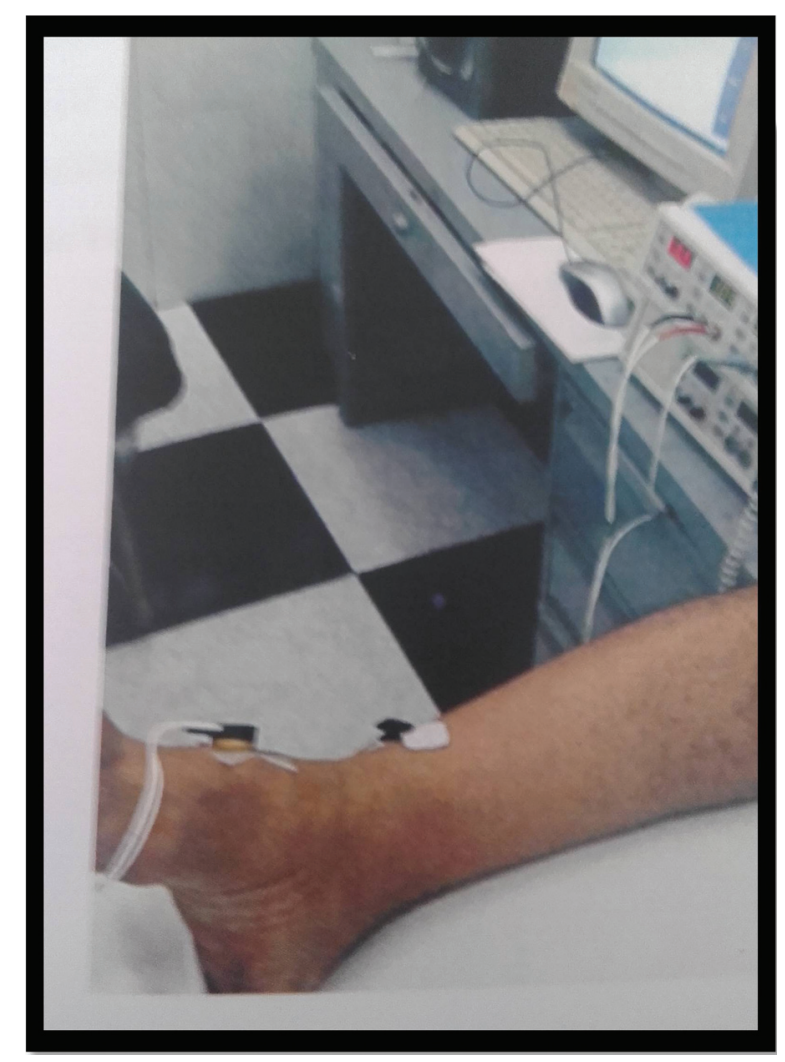

Monitoring of microcirculation with acetylcholine iontophoresis.

Table 1 Demographic data of included patients

\begin{tabular}{lcccc}
\hline Variables & \multicolumn{2}{c}{ Group I $(n=20)$} & \multicolumn{2}{c}{ Group II $(n=20)$} \\
\cline { 2 - 5 } & Age (years) & BMI $\left(\mathrm{kg} / \mathrm{m}^{2}\right)$ & Age (years) & BMI $\left(\mathrm{kg} / \mathrm{m}^{2}\right)$ \\
\hline Mean & 50.15 & 35.98 & 51.05 & 36.44 \\
SD & 4.27 & 4.69 & 4.60 & 6.15 \\
Maximum & 58.00 & 43.70 & 60.00 & 46.60 \\
Minimum & 41.00 & 29.00 & 45.00 & 27.50 \\
Range & 17.00 & 14.70 & 25.00 & 19.10 \\
\hline
\end{tabular}


Figures 3 and 4 show the mean values of microcirculation perfusion 'in perfusion units' before and after $\mathrm{ACh}$ iontophoresis treatment protocol at $\mathrm{A}$, $\mathrm{B}$, and $\mathrm{C}$ in both studied groups $(P<0.0001$ for all).

The $($ mean $\pm \mathrm{SD})$ percentage change in perfusion pretreatment and post-treatment at $\mathrm{A}, \mathrm{B}$, and $\mathrm{C}$ were $180.65 \pm 34.52,219.45 \pm 63.23$, and $269.60 \pm 49.79 \%$ in group I and $131.50 \pm 45.05,149.40 \pm 51.75$, and $236.95 \pm 51.85 \%$ for group II patients.

The pretreatment and post-treatment perfusion values (in perfusion units) and percentage change of perfusion (in \%) at $\mathrm{A}, \mathrm{B}$, and $\mathrm{C}$ were significantly higher in group

\section{Figure 2}

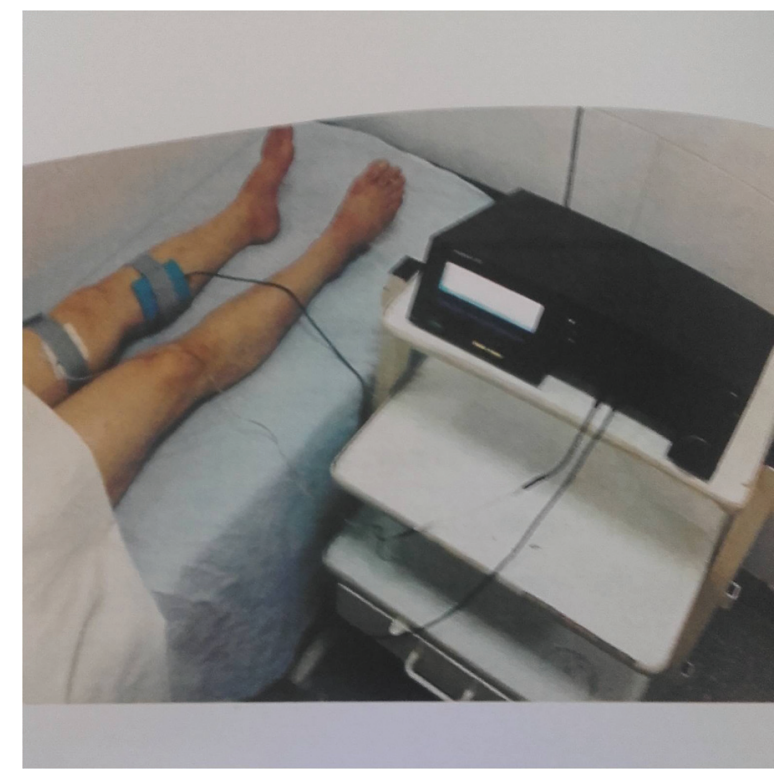

Procedure of therapeutic acetylcholine iontophoresis.

Table 2 Perfusion and percentage change in perfusion at baseline

\begin{tabular}{lccc}
\hline Variables & $\begin{array}{c}\text { Pretreatment } \\
(\mathrm{PU})\end{array}$ & $\begin{array}{c}\text { Post-treatment } \\
(\mathrm{PU})\end{array}$ & \% change \\
\hline Group I & $7.55 \pm 2.45$ & $24.55 \pm 8.24$ & $180.65 \pm 38.42$ \\
Group II & $4.08 \pm 1.30$ & $11.65 \pm 4.24$ & $131.50 \pm 45.05$ \\
$t$-value & 6.01 & 6.71 & 3.87 \\
$P$ value & $<0.0001$ & $<0.0001$ & $<0.0004$ \\
\hline
\end{tabular}

$\mathrm{PU}$, perfusion units.

Table 3 Perfusion and percentage change in perfusion at heating to $35^{\circ} \mathrm{C}$

\begin{tabular}{lccc}
\hline Variables & $\begin{array}{c}\text { Pretreatment } \\
(\mathrm{PU})\end{array}$ & $\begin{array}{c}\text { Post-treatment } \\
(\mathrm{PU})\end{array}$ & \% change \\
\hline Group I & $8.85 \pm 2.77$ & $25.75 \pm 10.17$ & $219.45 \pm 63.23$ \\
Group II & $5.00 \pm 1.62$ & $13.08 \pm 4.93$ & $149.40 \pm 51.75$ \\
$t$-value & 5.35 & 5.01 & 3.83 \\
$P$ value & $<0.0001$ & $<0.0001$ & 0.0005 \\
\hline
\end{tabular}

$\mathrm{PU}$, perfusion units.
I compared with group II patients as shown in Tables 2-4 and Fig. 5.

\section{Discussion}

$\mathrm{ACh}$ iontophoresis is a noninvasive technique used to deliver high local drug concentration causing cutaneous vasodilation without systemic side effects $[18,19]$.

According to our results, microcirculation baseline perfusion at room temperature was better in patients without compared with those with PN in line with many previous studies [20-24] that confirms the potential pathogenic role of functional microcirculation abnormalities in the pathogenesis of $\mathrm{PN}$ and can be explained by impaired nerve axon reflex-mediated vasodilatation or the Lewis triple flare response noticed in PN patients [21].

We also found that local warming to $35^{\circ} \mathrm{C}$, improved the perfusion in both studied groups with again much better response in patients without $\mathrm{PN}(P<0.0001)$ that agreed with the results of Arora et al. [23] with two differences; they raised the temperature to $44^{\circ} \mathrm{C}$ and included patients with combined PN and PVD 'before and after revascularization' as well as healthy individuals to show the importance of neuropathy in impaired cutaneous perfusion despite adequate correction of large vessel blood flow. Of note, both of our work and Arora et al. [23] study showed that improved perfusion after local heating was lesser than that achieved by iontophoresis which was not the case in another study by Christen et al. [25] that they explained by possible release of additional vasodilatory mediators other than nitric oxide in response to local heating considering that the latter study included 26 healthy individuals and non-diabetics.

According to our results, microcirculation perfusion after ACh iontophoresis improved by 269.60 and $236.95 \%$ in patients without and with PN, respectively, in line with Brooks and colleagues $[16,21,24]$, who stated that abnormalities of microvascular blood flow as assessed by $\mathrm{ACh}$

Table 4 Perfusion and percentage change in perfusion after short-term iontophoresis

\begin{tabular}{lccc}
\hline Variables & $\begin{array}{c}\text { Pretreatment } \\
(\mathrm{PU})\end{array}$ & $\begin{array}{c}\text { Post-treatment } \\
(\mathrm{PU})\end{array}$ & \% change \\
\hline Group I & $25.15 \pm 9.28$ & $69.70 \pm 18.89$ & $269.60 \pm 49.79$ \\
Group II & $149 \pm 5.44$ & $33.10 \pm 15.82$ & $236.95 \pm 51.85$ \\
$t$-value & 4.24 & 6.64 & 2.03 \\
$P$ value & 0.0002 & $<0.0001$ & 0.049 \\
\hline
\end{tabular}

$\mathrm{PU}$, perfusion units. 
iontophoresis were evident in diabetics but became more marked with the development of microvascular complications such as PN.

On the other hand, according to Beer et al. [26], both endothelial dependent (to $\mathrm{ACh}$ iontophoresis) and independent (to sodium nitroprusside iontophoresis) reactivity were significantly blunted in diabetics compared with healthy controls but regardless of the presence or absence of microvascular or macrovascular complications.

Regarding the therapeutic use of iontophoresis, there are many limitations including unknown and variable delivered drug dose that depends on the current intensity and duration of exposure [27,28] as well as electrical characteristics of human skin [29].

For $\mathrm{ACh}$ iontophoresis in particular, there is an additive limitation that includes rapid offset of the drug action once the current was terminated that may be explained by ACh esterase [30].

Despite the above-mentioned limitations, we tried in the current study to use $\mathrm{ACh}$ iontophoresis as a therapeutic tool depending on two important facts; first, there are two ways of current application protocols; continuous and multiple current pulses separated by current-free interval protocols [6] and the second thing that change of the current duration, intensity, and frequency as well as the duration of rest time before and in between stimulations may all enhance delivery of the drug [28].

So we used the multiple current pulse protocol, a relative higher current intensity ' $3-5 \mathrm{~mA}$ ', for rather longer duration of ' 15 min' and with repeated frequency of 'three sessions/week for 2 weeks'.

Figure 3

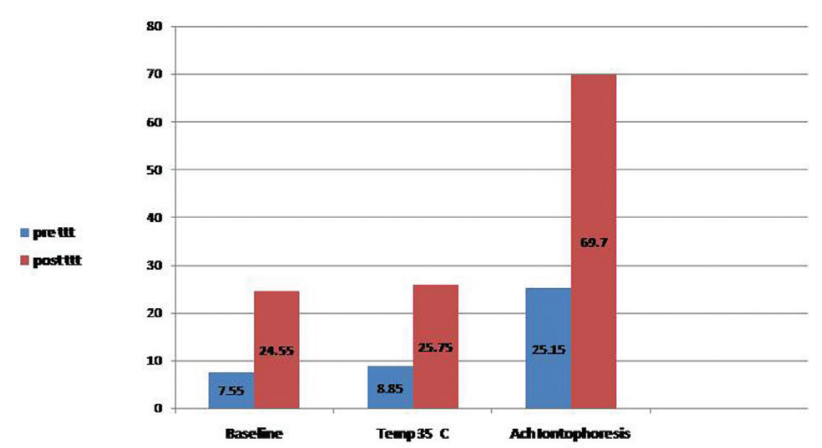

Pretreatment and post-treatment perfusion in group I.
Close to our protocol, Murray et al. [6] have demonstrated that increasing $\mathrm{ACh}$ iontophoresis time from 2 to $5 \mathrm{~min}$ led to more sustained vasodilation with increased perfusion in patients with systemic sclerosis.One more important note, we believe that applying the iontophoresis process in the thighs in our therapeutic maneuver may decrease the risk of prolonged current application depending on the fact that current density equals the current intensity divided by cross-sectional skin area in contact with the electrodes 'expressed in $\mathrm{mA} / \mathrm{Cm}^{2}$ ' [27].

Even more prolonged current duration and intensity was safely used before in the induction of hypohydrosis by tap-water iontophoresis at an intensity of $15-20 \mathrm{~mA}$ applied to each palm or sole for $30 \mathrm{~min}$ per session (vs. only 3-5 $\mathrm{mA}$ for $15 \mathrm{~min}$ in our work) for 10 consecutive days, followed by 1-2 maintenance sessions per week [31].

According to our results, percentage change in the improvement of local skin perfusion after sessions of

\section{Figure 4}

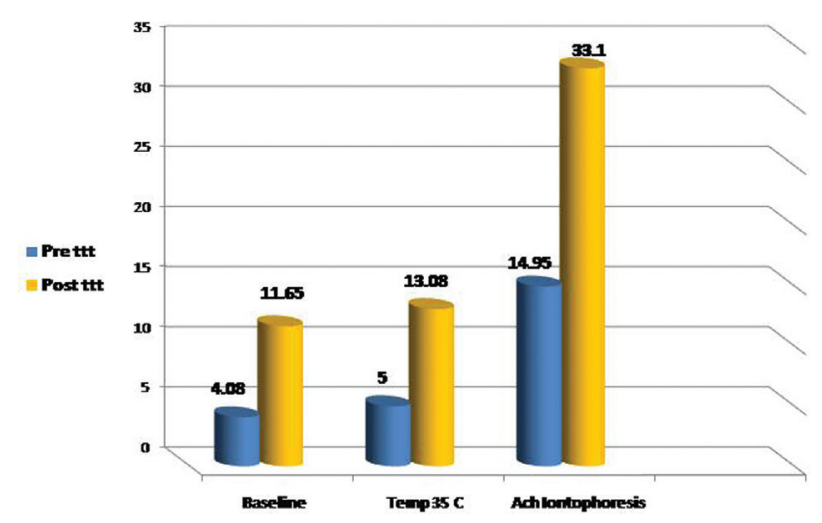

Pretreatment and post-treatment perfusion in group II.

Figure 5

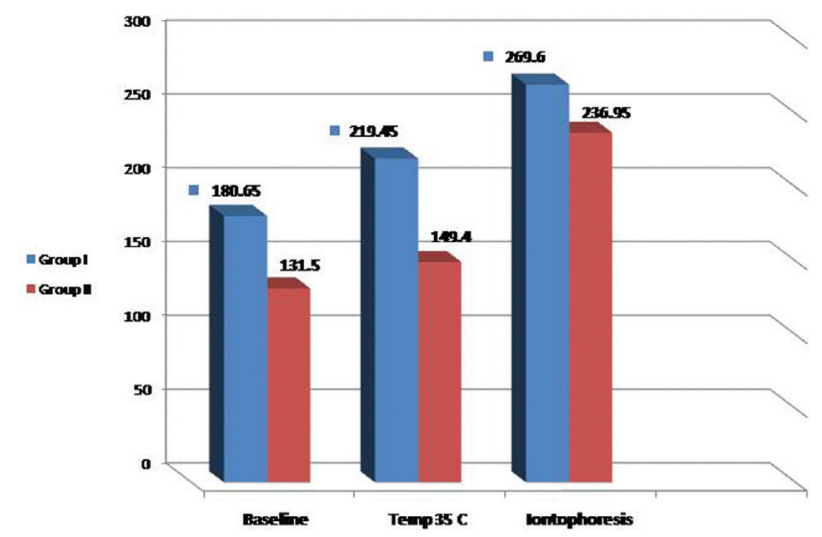

Percentage change in perfusion in the two groups. 
ACh iontophoresis for 2 weeks was close to the results of the studies by Durand and colleagues [32,33], who found improved cutaneous perfusion after $\mathrm{ACh}$ iontophoresis with biphasic response with early and transient peak that fade off gradually and reincreased after 10 days.

The rapid peak may be related to endothelium-dependent vasodilation through muscarinic receptor $\mathrm{M} 3$ stimulation, whereas the late response involves muscarinic receptor as well as prostaglandins [32] (Figs 4 and 5).

\section{Conclusion}

Therapeutic ACh iontophoresis may be a potentially useful tool to enhance cutaneous microcirculation in diabetics and its complications like PN in which local alteration of microcirculation may play a role in its pathogenesis.

\section{Financial support and sponsorship Nil.}

\section{Conflicts of interest}

None declared.

\section{References}

1 Korula M. Iontophoretic delivery of drugs. Indian Anaesth Forum 2004; 94:1484-1488

2 Eisenach JH, Atkinson JL, Fealey RD. Hyperhidrosis: evolving therapies for a well-established phenomenon. Mayo Clin Proc 2005; 80:657-666.

3 Goyal M, Kumar A, Mahajan N, Moitra M. Treatment of plantar fasciitis by taping vs. iontophoresis: a randomized clinical trial. J Exercise Sci Physiother 2013; 9:34-39.

4 Zecuity. NuPathe's Zecuity approved by the FDA for the acute treatment of migraine. Available at: http://ir.nupathe.com/press-releases. (Accessed 25 April 2013)

5 Zhao M, Song B, Pu J, Wada T, Reid B, Tai G, et al. Electrical signals control wound healing through phosphatidylinositol-3-OH kinase-gamma and PTEN. Nature 2006; 442:457-460.

6 Murray AK, Moore TL, King TA, Herrick AL. Vasodilator iontophoresis: a possible new therapy for digital ischaemia in systemic sclerosis?. Rheumatology 2008; 47:76-79.

7 Cordovil I, Huguenin G, Rosa G, Bello A, Köhler O, De Moraes R, et al. Evaluation of systemic microvascular endothelial function using laser speckle contrast imaging. Microvasc Res 2012; 83:376-379.

8 Morris SJ, Shore AC. Skin blood flow responses to the iontophoresis of acetylcholine and sodium nitroprusside in man: possible mechanisms. J Physiol. 1996; 496:531-542.

9 Puissant C, Abraham P, Durand S, Humeau-Heurtier A, Faure S, Rousseau $\mathrm{P}$, et al. Endothelial function: role, assessment and limits. J Mal Vasc 2014; 39:47-56.

10 Sauvet F, Mahé G, Chennaoui M, Langrume C, Vasseur M, Abraham P, et al. Acetylcholine chloride as a potential source of variability in the study of cutaneous vascular function in man. Microvasc Res 2011; 82:190-197.

11 Ruderman A, Williamson N, Brownlee M. Glucose and diabetic vascular disease. FASEB J 1992; 6:2905-2914.
12 Brownlee M, Cerami A, Vlassara $\mathrm{H}$. Advanced glycosylation end products in tissue and the biochemical basis of diabetic complications. N Engl J Med 1988; 318:1315-1321.

13 Asad A, Hameed MA, Khan UA, Ahmed N, Butt MU. Reliability of the neurological scores for assessment of sensorimotor neuropathy in type 2 diabetics. J Pak Med Assoc 2010; 60:166-170.

14 Tanenberg RJ. Diabetic peripheral neuropathy: painful or painless. Hosp Physician 2009; 45:1-8.

15 Elashmaoui A, Nashaat M, Abdelghany H. Endothelial dysfunction and microangiopathic changes in first degree relatives of patients with type 2 diabetes assessed by iontophoresis. European Society For Microcirculation: 23rd Conference, Lisbon, Portugal, Microcirculation and Vascular Biology: a basis for research and a reason for life. J Vasc Res 2004; 8:319-324.

16 Brooks BA, Melennan SV, Twigg SM, Yu DK. Detection and characterization of microcirculatory abnormalities in the skin of diabetic patients with microvascular complications. Diab Vasc Dis Res 2008; 5:30-35.

17 Singh PK, Kumar S, Easwari TS, Shukla VK, Chaudhary R, Verma P. Iontophoretic delivery of drugs: maximizing treatment effectiveness. Int J Pharm Sci Letters 2011; 1:28-33.

18 Kellogg DL Jr, Crandall CG, Liu Y, Charkoudian N, Johnson JM. Nitric oxide and cutaneous active vasodilation during heat stress in humans. $\mathrm{J}$ Appl Physiol 1998; 85:824-829.

19 Kellogg DL Jr, Johnson JM, Kosiba WA. Selective abolition of adrenergic vasoconstrictor responses in skin by local iontophoresis of bretylium. Am J Physiol 1989; 257:1599-1606.

20 Kelly J, Cassella JP, Ashford RL, Thomkin GH. An iontophoretic study of the endothelial response in the diabetic foot with symmetrical sensory neuropathy. Foot 2001; 11:144-150.

21 Hamdy O, Abou-Elenin K, LoGerfo FW, Horton ES, Veves A. Contribution of nerve axon reflex related vasodilation to the total skin vasodilation in diabetic patients with and without neuropathy. Diabetes Care 2001; 24:344-349.

22 Zimny S, Dessel F, Ehren M, Pfohl M, Schatz H. Early detection of microcirculatory impairment in diabetic patients with foot at risk. Diabetes Care 2001; 24:1810-1814.

23 Arora S, Pomposelli F, Logerfo FW, Veves A. Cutaneous microcirculation in the neuropathic diabetic foot improves significantly but not completely after successful lower extremity revascularization. J Vasc Surg 2002; 35:501-505.

24 Quattrini C, Harris ND, Malik RA, Tesfaye S. Impaired skin microvascular reactivity in painful diabetic neuropathy. Diabetes Care 2007; 30:655-659

25 Christen S, Delachaux A, Dischl B, Golay S, Liaudet L, Feihl F, et al. Dose dependent vasodilatory effects of Acetylcholine and local warming on skin microcirculation. J Cardiovasc Pharmacol 2004; 44:659-664.

26 Beer S, Feihl F, Ruiz J, Juhan-Vague L, Aillaud MF, Wetzel SG, et al. Comparison of skin microvascular reactivity with hemostatic markers of endothelial dysfunction and damage in type 2 diabetes. Vascu Health Risk Manag 2008; 4:1449-1458.

27 Kalia YN, Naik A, Garrison J, Guy RH. Iontophoretic drug delivery. Adv Drug Deliv Rev 2004; 56:619-658.

28 Tesselaar E, Sjoberg F. Transdermal iontophoresis as an in-vivo technique for studying microvascular physiology. Microvasc Res 2011; 81:88-96.

29 Ramsay JE, Ferrell WR, Greer IA, Sattar N. Factors critical to iontophoretic assessment of vascular reactivity: implications for clinical studies of endothelial function. J Cardiovasc Pharmacol 2002; 39:9-17.

30 Walch L, Norel X, Leconte B, Gascard JP, Brink C. Cholinergic control of human and animal pulmonary vascular tone. Therapie 1999; 54: 99-102.

31 Thomas I, Brown J, Vafai J, Schwartz RA. Palmoplantar hyperhydrosis: a therapeutic challenge. Am Fam Physician 2004; 69:1117-1121.

32 Durand S, Tartas M, Bouye P, Koitka A, Saumet JL, Abraham P. Prostaglandins participate in the late phase of the vascular response to acetylcholine iontophoresis in humans. J Physiol 2004;561:811-819.

33 Ward JD. Upright posture and the microvasculature in human diabetic neuropathy: a hypothesis. Diabetes 1997; 46:S94-S97. 